\title{
MOVING TOWARDS DIGITAL GOVERNANCE OF UNIVERSITY SCHOLARS: INSTIGATING A POST-TRUTH UNIVERSITY CULTURE
}

\author{
Lennart Nørreklit, Aalborg University
}

Lisa Jack, University of Portsmouth

Hanne Nørreklit, Aarhus University

\begin{abstract}
Purpose: Governance models are increasingly driven by information technology and are being applied to measure the performance of all kinds of organisational activity including that of universities. This paper investigates whether the language embedded in the production and use of data for governance models based on information technology (IT) facilitates a governance culture that excludes the scholarly insights of university professionals.
\end{abstract}

Methodology: Theoretically, the paper draws on the language philosophy of the live language games of capable habitus-based practices and that of the digital language of IT systems. The theoretical framework is illustrated by examples of university practices.

Findings: We argue that the reductive, digital language embedded in IT-based performance measures might destroy the live language game through which scholars of universities produce and develop complex cognitive conceptual habitus. Managers in thrall to the digital language of control accessible via IT can use it to create operational paths that crowd out the free cognitive conceptual habitus of the university scholars. Accordingly, the culture of the corporate university is moving towards a post-truth state.

Implications: Digitally based management systems have created a palpable change in university work place narratives, but the extended use of these systems has not solved governance problems. The situation suggests that the role of universities as the foundation for the whole project of enlightenment and knowledge-based society is threatened.

Originality/Value - Our paper provides a novel insight into the changing discourses in university governance in an era increasingly characterised as post-truth.

Key words: performance measurement, habitus-based language, university scholars, digital language, post truth. 


\section{INTRODUCTION}

In recent decades, most publicly funded western universities have been subjected to the governance principles of new public management (Craig, Amernic and Tourish 2014). The corporate university has replaced a profession-driven governance system that had developed over centuries in western universities, and its adoption implies universities should be governed through responsible management in a similar manner to a corporation. The university is expected to be three different types of institution simultaneously: an academic community, a bureaucracy, and a business corporation (Barcan 2013) The academic is expected to embody (or as Barcan (2013, p. 69) puts it, be the victim of and vessel for) the physical, intellectual, and emotional work involved in integrating three sets of institutional demands.

The governance paradigm is dominated by the notion of excellence and quantitative thinking. Following Readings (1996) prescient work The University in Ruins, Barcan (2013, p. 68) states that content 'is being supplanted by the notion of "excellence". Excellence is a "unit of currency within a closed field' - a set of measures that assume that there is a 'single standard...in terms of which universities can be judged, irrespective of content.' Accelerated by the capacity of information technology (IT) to collect and calculate (big) data, governance tools are increasingly observed to capture excellence around the use of all kinds of performance measures, such as, journal rankings, league table placings, student survey scores, external impact, funding, on time delivery, etc. (Barcan 2013; O’Neil 2016).

The increased collection and calculation of data might provide a certain knowledge foundation for controlling the university managers and employees that will make them more accountable to society (Messner 2009). However, there are also some dysfunctional effects of living with a quantified form of control. For instance, a bureaucratic top-down implementation of standards of performance measurement encourages researchers to superficially conforming to norm through short-term and opportunistic behaviour (Humphrey and Gendron 2015; Gendron, 2015; Craig et al. 2014; Pianezzi, Nørreklit and Cinquini, Forthcoming). There may be an acceleration in quantity of research outputs, but the research content might become less innovative and intellectually stagnant. Analysing the current academic ranking systems, Adler and Harzing (2009, p. 72) suggest that '...current systems are dysfunctional and potentially cause more harm than good, a temporary moratorium on rankings may be appropriate until more valid and reliable ways to assess scholarly contributions can be developed'. Burrows 
(2012, p. 355) finds that metrics: '...increasingly function autonomously as a data assemblage able not just to mimic markets but, increasingly, to enact them'. Furthermore, the university is splitting an object (its reputation for research) into a good category (which is idealised) and a bad category (which is despised) (Craig, Amernic and Tourish 2014, p. 15). Doing so offers a defence mechanism for the university, in that it can keep the good and bad separated and controlled. The method helps avoid anxiety situations by retreating into bureaucracy.

While the content of what we research and teach might not matter in the measurement of the excellent university and the version of success and failure they produce, it is of concern to politicians and to the public because the university is seen as central to economic and ideological investments in the State (Barcan 2013). Academic values still exist but might have to contend with notions of expertise and the story of 'the managers who built the excellent university' (Barcan 2013, p. 87). However, the hybridity of the corporate university leads to dissonance, for 'when traditional and emergent institutional forms meet and overlay each other, there is an unavoidable collision of logics, purposes, values and demands, resulting in complex and dynamic modes of existence' (Barcan 2013, p. 87). In addition, the governance paradigm might give extensive space to the stresses, strains, and oppressions affecting the members of the new economy (Thrift 2005, p. 152; Franco-Santos and Doherty 2017). The competitive proving of merit, the generation of anxiety and fantasies of control, lead to the fetishising of speed, reachability, multitasking, and synergy; and an environment that risks being unorchestrated, distracting and delusional (Barcan 2013). Craig, Amernic and Tourish (2014) state that the extreme measurement and audit culture of modern universities is a psychotic one, as it is "showing signs of becoming "delusional"; of having a defective "contact with reality"; and of being paranoid schizoid' (p. 6).

Some studies point to academic resistance to the disciplining power of performance measurement (Kalfa, Wilkinson and Gollan 2018; Alvesson and Spicer 2016; Anderson 2008). For instance, Anderson (2008) describes academics as intrinsically motivated to produce academic work and devoted to the defence of academic autonomy. However, academics mainly resist through more or less ideologically embedded academic writings (Worthington and Hodgson 2005), hidden or low-profile actions, weakening the weapons they have to hand and their effects (Anderson 2008; Kalfa et al. 2018). Indeed, individual researchers who must embody and absorb the psychotic culture that arises from being continually audited, might feel constrained in putting forward arguments and expressing themselves academically: 'How 
might we engage critically with the multiple moments in which individuals report being at breaking point, say "my work is crap" or "I'm going to be found out" - as well as those moments of gratuitous attack and cruelty, so often seen - for example - in anonymised referee processes (yet rarely challenged) ...?' (Gill 2009, p. 229)

These findings give reason to be anxious about whether the extreme measurement that is accelerated by IT systems jeopardises the scholarly voices of the university academics. This paper questions whether the IT-based performance measurement models applied in the management of the corporate university facilitate a governance culture that invalidates the scholarly insights of university professionals.

We address the question both theoretically and empirically. Theoretically, we draw on Wittgenstein's later work (1953) that conceives practice as a life form organised around language games that constitute the social factory (L. Nørreklit 2017b) that must function pragmatically. Emphasising the cognitive complexity embedded in the live language games of capable professional practices, we use the term a habitus-based language game ${ }^{1}$. We contrast this habitus-based language game with the digital form of language guiding IT systems, which has similarities with that found in the philosophy of language of Wittgenstein's earlier work, Tractatus Logico-Philosophicus (1921). Contrasting this philosophy of language with that of a habitus-based language game, we analyse the implications of changing the language of governance of live language games into digital language. We argue that governance by digital scripts destroys the connections to the logos of the habitus-based language game and thereby the insights of professionals are diminished. The digital scripts pave the way for excessive use of pathos and ethos and hence to a post-truth state with scant regard for truth (D'Ancona 2016).

Starting from this theoretical basis, we empirically investigate the language driving the production and use of the IT-based measurement systems of universities and the evidence that these can develop governance modes that oppress the scholarly voice of university academics. Our empirical findings confirm our theoretical proposition that the production and use of ITbased measurement systems for university governance interferes with and inhibits the social

\footnotetext{
${ }^{1}$ Generally, habitus refers to individual's or group of people's pattern of embodied dispositions that organise the ways in which they perceive the environment and react to it (https://en.wikipedia.org/wiki/Habitus) The term originates with Aristotle, but has since been used by various specialists. More recently Bourdieu uses it as a core concept in his interpretation of sociology (Bourdieu 1990).
} 
factory of university scholars by taking control of the concepts and language of the social interaction and increasingly undermining self-controlling individuals on all levels. Thus, ITbased university governance is crowding out the habitus-based language game of university scholars.

Our analysis contributes to the research reviewed above by revealing that the digital language of performance measures has wider implications than making university scholars accelerate their output results, adopt to less innovative norms and stagnate intellectually. We argue that language of the university scholars is crowded out. Hence, the scholarly forum within which to argue and resist is jeopardized.

Using universities as a site to investigate these changes in governance is justified because of the unique role that they have in society. They provide a mainly secular, scientific basis for thought that is distanced from biases of belief, customs and tradition. If they are unable to fulfil this role then the whole project of enlightenment and knowledge-based society will lose its institutional foundation. However, we think that our study is also justifiable on the grounds that most other public institutions in western societies are also subject to new public management, and therefore face a similar measurement and audit culture.

The article continues by describing the focal research problem and the method chosen to address it. Next, we explain the habitus-based language game as a basis of production of meaning versus the digital language of the scripted IT systems and the implication of applying the latter in the governance of the live language games producing the social factory. Subsequently, we illustrate the problem by reference to some contemporary university practices. The final section summarises the results and places them in the context of a general contention that we live in an era of post truth.

RESEARCH PROBLEM AND METHOD

Changes in university governance

The free cognitive habitus-based university governance 
The European university tradition is based on the idea of a language game driven by free cognitive habitus. Since the establishment of Bologna University in $1088^{2}$, European universities have been organised as autonomous units governed by the academic community. The academic community has been largely self-regulating, which enabled its membership of scholars to set their objectives and the criteria on which they can legitimately be evaluated for themselves. A core characteristic of a university is the idea of academic scholars' freedom to develop their thinking. The root of universities' legal right to be a place where scholarly thoughts could develop independent of any other power is considered to be Authentica habita (1155), which grants protections to scholars and students at Bologna University not to suffer intervention by various forms of political authorities (Benson, Constable and Lanham 1991). In the current era, more than eight hundred university rectors have signed the Magna Charta Universitatum (Bologna, 18 September 1988) ${ }^{3}$, which proclaims scholarly freedom to be a fundamental principle in the governance of universities: 'To meet the needs of the world around it, its [university] research and teaching must be morally and intellectually independent of all political authority and economic power. (...) Freedom in research and training is the fundamental principle of university life, and governments and universities, each as far as in them lies, must ensure respect for this fundamental requirement'.

An important part of the scholarly academic habitus of European universities is the cultivation of dialogic scholarly interaction based on Socratic questioning and conceptual reasoning (Mejlgaard, Aagaard and Siune 2002; Kristensen, Nørreklit and Raffnsøe-Møller 2011). Reasoning should set the criteria for what is true or false and right and wrong. The fact that power is the only alternative to arguments has been the reason for scientific argumentation, however imperfect that argumentation may be.

University communities are social factories (L. Nørreklit 2017b) of cognitive complexity and dialogical interaction. The habitus-based language game of scholarly argumentation makes up the social factory that is to produce academic results. The participating scholars are assumed to be self-motivated and responsible individuals. They are free agents in the sense that they act

\footnotetext{
${ }^{2}$ https://www.unibo.it/en/university/who-we-are/our-history/university-from-12th-to-20th-century

${ }^{3}$ http://www.magna-charta.org/magna-charta-universitatum/the-magna-charta-1/the-magna-charta
} 
on their own initiative, but they should also be custodians of scholarly practice, that in turn should have the well-being of people and society at its heart. However, universities have been criticised for failing to take care of the needs and demands of society, which might partly explain the rise of the corporate university (Barcan 2013; Kristensen et al. 2011).

\section{The corporate university}

Universities are involved in an institutional contest where demands are placed on them by various powerful stakeholders such as governmental agencies, students, firms, not-for-profit accreditation associations, and media organisations. The changing institutional environment implies that external-origin objectives, norms, and procedures are formulated and implemented in many European universities. Performance measures are implemented to capture the degree to which the universities meet the demands of excellence and thereby inform the decision making of external stakeholders. These measures include quantitative measures of employee appraisal, course descriptions, student satisfaction surveys, journal rankings, and those used in professional accreditations such as AACSB (The Association to Advance Collegiate Schools of Business, 2018) and EQUIS (European Quality Improvement System, 2018). Further league tables and rankings are produced in media magazines such as the Financial Times (2016) and Forbes, while publishers produce citation indices and impact factors. These external-origin objectives and measures are meant to support governance at the overall university level and not to be applied to evaluate individual researchers, but the corporate university is organised as a top-down hierarchy where overall objectives and targets are deployed further down the organisation to the various departments and units, and ultimately to the individual researcher.

IT systems make it possible to accumulate, retrieve, transmit, and manipulate information from users across social space with a speed and to an extent never seen before. The language of IT is a digital-based language that is reductive and different from the live language of university scholars. This is not necessarily a problem because reductive language such as that of mathematics has always been used as an integrated part of understanding and developing complex practices, but when the institutional environment of the corporate universities mandates IT-based measurement systems to control complex social practices such as scholarly research it might become a problem. If IT-based measurement systems become removed from scholarly language, it might jeopardise scholarly practice. On this basis we raise the following research questions 
Do the IT-based performance measurement models applied in the governance of the corporate university crowd out the habitus-based scholarly language?

\section{Method}

Addressing this research question on the state of the habitus-based scholarly language at corporate universities involves investigating the nature of the live language game that embodies the social factory versus the digital language embedded in IT and the implications of changing the language of governance to a digital language. More specifically, we draw on Wittgenstein's later work (1953) that conceives practice as a life form organised around language games that constitute the social factory and on pragmatic constructivism to outline what is required to create functioning practice (L. Nørreklit 2017a, b.) As mentioned above we use the term habitus-based language game to emphasise the cognitive complexity embedded in the live language games of capable practices such as those constituting scholarly university practices. Subsequently, we identify the language characteristics of IT systems. The language of IT encapsulates an analytical idea of meaning derived from logical positivism. This is further guided by a form of digital language close to that found in the philosophy of language of Wittgenstein's earlier work, Tractatus Logico-Philosophicus (1921).

By contrasting this philosophy of language with that of the habitus-based language game, we analyse the effects of the comprehensive use of IT in social control of the live language games. We argue that the governance by digital scripts destroys the connections to the logos of the habitus-based language game and thereby devalues the insights of the professionals.

On this theoretical basis, we raise a concern about the comprehensive use of IT-based measurement systems in the management of universities. Investigating the concern empirically, the paper analyses the language driving the production and use of the IT-based measurement systems of contemporary university practices. Drawing on our theoretical framework, we analyse the nature of the language in the IT-based scripts that is implemented for the governance of the corporate university and highlight its implications for the free cognitive conceptual habitus of university scholars.

Specifically, the article examines the language governing the production and use of measurement systems for the evaluation of teaching and research at universities, with a particular focus on business education. First, we studied the formal scripts determining how 
student and researcher evaluations are produced globally, nationally and locally. Over the last fifteen years, using online questionnaires to evaluate teaching quality has become commonplace at most universities. To uncover the construction of such teaching evaluation systems, we studied the UK National Student Survey established in 2005 (see, for example, Burgess, Senior and Moores 2018) and the Teaching Excellence Framework (TEF 2018), that is based partly on the results of the aforementioned NSS, that were first reported in 2017. In the business school context, journal rankings have become essential tools used by management to evaluate university research, and the dominant parties in the production and use of globally applied journal rankings are the Financial Times, Thomson Scientific's Journal Citation Report (JCR), and the Google Scholar Citations indexes; we analyse the publicly available formal scripts and the research on the production of each of those indexes. Moreover, we study the production of the ranking lists developed nationally and locally by university managers and the production of publication points. In the UK, the Research Excellence Framework (REF), first introduced in 1986 as the Research Assessment Exercise (RAE), is an additional peer-reviewbased ranking exercise that takes place every 6 or 7 years that examines the published outputs, impact cases and research environment of universities (see McNay 2015; Pidd and Broadbent 2015; Murphy and Sage 2014).

Second, we investigate how the measurement systems relating to teaching and research are used in practice. The topic is extensively discussed among researchers. The current research is based on publicly available scripts on the use of systems for teaching and research evaluation with no reference to personal experiences. However, the findings is limited by the conditions of our case material. The selected scripts describes system problems of research governance at which there is a comprehensive and prominent body of publications. A part of these pubications is covered in the paper to illustrate some facets of the problem.

The analysis provides the basis for evaluating the possible effect of some dominating IT-based governance systems on the free cognitive conceptual habitus. Below, we present our theoretical analysis of the research question and subsequently the empirical investigation.

\section{HABITUS-BASED LANGUAGE GAME AND DIGITAL LANGUAGE - A THEORETICAL ANALYSIS}


This section explains the philosophy of the habitus-based language game as a basis of production of meaning and professional social practice including scholarly university practices. Subsequently, we identify the characteristics of the language of the scripted IT systems and the implications of applying them in the governance of the live language games producing the social factory.

\section{Habitus-based language game}

\section{\$ Language game and pragmatic construction of reality}

According to the older Wittgenstein (1953), human life forms and practices unfold in language games. A language game is a story in which narration is blended with other forms of action. The stories are influenced and controlled by various narrations by participating actors and underlying narratives that are also parts of the language game. The language games produce stories in which people develop social characters and the knowledge and skills that nurture practices to help construct material and human relations and to act to produce performance. Language games embedded in a physical and cultural environment produce physical and social realities. The story produces memories and fosters skills through which knowledge accumulates and becomes ever more complex and advanced. Overall, the language game makes up the social factory that produces not only machines and products but also social human beings capable of producing intentional results.

The narration of language games is the basis of organising actions and events of human lifeforms and practices, and of structuring cooperation in accordance with desires, knowledge and skills. Through narration, actors create a relational structure between themselves and the world surrounding them, which constitutes their (co-)construction of reality. However, the language toolbox contains a multitude of words, figures, images, phrases, concepts, arguments, etc. that the participating actors can draw upon and assemble in numerous forms of narratives. Accordingly, a story may be told through different narratives, depending on who tells it: it may even appear as different stories. However, some narratives function well and produce results in specific activities, while other narratives do not.

Drawing on pragmatic constructivism (Nørreklit, Nørreklit and Mitchell 2010, Nørreklit 2011, Nørreklit L. 2017a, 2017b), we argue that for actors and organisations to relate successfully to their environment their narration must outline relevant factual opportunities. There can be no 
action, if there are no opportunities. But for the opportunities to be more than figments of the actor's imagination, they must be grounded in fact. Additionally, owing to the individuality of the cognitive habitus of employees and to the use of complementary professions, the role of management cannot simply be to dictate their own narrative to the employees. Their task is to organise and enforce the production of a narrative that enables employees to work to the best of their ability. To achieve this, employees must be involved in the narration, which means that managers must orchestrate a narration process in which the employees may participate. A manager, that devises the narrative without any input from employees cannot incorporate the special capacities and motivations of the employees, and that omission could lead to sub-par performance. Finally, it is important that the narratives are linked to human values and hence are ethical. Ethics is an aspect of social behaviour that aims to transform social interaction into something that is beneficial for the members of society. It promotes actorship as a world of creative co-actorship that promotes the construction of social conditions favouring human values and rejects activities that are detrimental to human co-actorship. Functioning language games integrate values, possibilities, and factual conditions and thereby successfully control human activities. Accordingly, functioning language games constitute basic conditions for fruitful structuration.

To establish the required common understanding, communication must be guided by advanced communicative competences in which the different logos of the participants are set to mirror and interact with each other. Therefore, to establish common understanding, communication needs to be controlled by dialogues. If communication is controlled by monologues, then it dictates and its ability to coordinate and produce understanding is undermined. A monologue allows no game because there is nobody to play with, players are so to speak not allowed.

It is through the production of narratives that a communication can produce a story that fulfils the above criteria. However, no matter how much we know about the story, our knowledge is an abstraction; nevertheless, it may be true. We argue that although there is no absolute evidence of a story, one can only approach the truthfulness of it through a pragmatic truth of the narration, which involves checking the validity of expectations against the outcome of relevant actions. This presupposes using criteria for evidence that are scrutinised and improved by research. Accordingly, we use pragmatic criteria to uncover the differences between realistic constructs and illusory ones. The pragmatics of narration is the vehicle of successful reality construction. Without such pragmatics the world of narration is a world of translation alone. 
Action, succeeding, suffering, construction, failing would be merely narratives without a story to be told behind the narrative.

Below, we explain the complexity of the cognitive process that professional practices might apply to manage the social factory to produce intentional results; that is, to produce pragmatic truth.

\section{$\S$ Cognitive conceptual habitus}

To establish a relation between narrative and story, between ideas and reality, humans develop a set of cognitive skills in the form of concepts and abilities to observe, analyse and act. Without these concepts and forms of understanding, narratives would be sounds or signs devoid of meaning. These skills can enable humans to create and control their activities to produce intentional results - including professional practices - accumulating knowledge and add details, aspects and layers of all possible kinds of insight around the integration of facts, possibilities, values and communication. The complex development of human cognition produces multi-layered concepts enabling sophisticated usage and reflection, and it is through such multi-layered complexities of cognition that we express with the notion of conceptual habitus. The concept of habitus encapsulates the live language game producing a human cognition and understanding which is multi-layered, constantly developing.

Generally, concepts are assumed to consist of some kind of content, which is the cognitive meaning or idea embedded in the concepts, and a form of reference, which is the set of things in the world that are assumed to fit the conceptual content (Nørreklit L 2011, 2017a, 2017b). However, concepts cannot be understood only by reductionist definitions that create boundaries to their reference of extension. Concepts are understood and delimited by understanding their function in the reality construction of the practice or life form. Words and numbers are symbols that acquire meaning by their usage according to certain rules in specific language games. Accordingly, definitions that delimit the extension of a concept do not produce the understanding but presuppose an understanding of the concept. A growing conceptual habitus provides abilities to advance conceptual understanding, obtain high level conceptual structuration, and thereby to advance performance in the complex situations of real life. The richness of the conceptual habitus is a condition for professional cooperation, work, problem solving, and development of first-class solutions. By enabling a realistic construct, a proper conceptual structure should make it possible to distinguish a story and fiction, truthfulness and 
lies, correctness and error, or at least raise doubt if it is unclear whether there is a story or fiction, etc.

To develop knowledge and conceptual structures that lead to functioning activities, a logos-driven cognitive habitus is important. Logos covers everything humans are able to establish through various forms of sound reason. It provides the quality of the argument and analysis, which in practice is the feasibility of the knowledge of the situation and how things function (Aristotle 367BC-322BC). Put differently, the narrations might be governed by words, phrases and arguments that are emotional in nature and reference authorities, credibility and power, and hence the participants knowledge and interaction is based on pathos and ethos respectively.

In a knowledge society, logos is of utmost importance. Logos presupposes a culture and mindset of ataraxia, that is, a state of equanimity in interpersonal affairs. If for some reason, the logos becomes insignificant then the professional knowledge-habitus becomes insignificant and our language games do not produce an advanced cognitive habitus creating intentional outcomes. In addition, logos is a basis for judging and controlling ethos and pathos, avoiding favouritism and prejudice. If logos is sidelined, then management is produced through authority/emotionally driven communication and hence based purely on ethos and pathos. But without logos we operate in a post-truth situation.

\section{$\S$ Scripts}

Scripting plays an increasing role in the social factory involving several people communicating. Their scripts suspend the living flow of language because scripts do not disappear like other forms of expression. Scripts continue to emit their message as if they were expressions of an invisible power working against the social factory; apparently overruling interactive human reflection. However, scripts lend endurance to the message that enables a focus on reflection and concept development, which is important to the development and accumulation of knowledge and creation of specialised and professional knowledge that improves over time. In addition, it enables the construction of larger organisations, cultures and states (and thus bureaucratic control). The laws of society are authoritative scripts, which everybody must follow, although there exist special procedures with which these texts can be changed. Differently, research scripts are live scripts that the reader does not need to subscribe to or 
follow. Therefore, scripts in research are tools for researchers to critically reflect upon and change as their research produces new knowledge.

A special form of scripting is produced through the use of symbolic - or formal - languages such as those of maths and logic to produce models and theories in the form of formulae with a special logical grammar. The symbolic languages instil unambiguity, precision and clarity, which in addition furthers measurement and calculation. Thereby the symbolic scripts facilitate construction of symbolic or formal language systems that reflect and potentiate special aspects of the conceptual habitus by disregarding all other aspects. Such a script represents a cognition that is formal, but completely without habitual complexity. In scholarly practices, symbolic scripts are embedded in life forms, influencing the language games. Scientific and professional practices are impossible without them. However, they function as common reference points for professional users, who all have habitual complex concepts about the topics that are represented symbolically. Moreover, it is the independent judgement of the professionals, based on their cognitive habitus, whether they believe or are sceptical of the scripted representations. Without the cognitive habitus one cannot really understand and use theories. The symbolic scripts are backbones in live language games among scientists and professionals. These scientist and professional users have very complex habitual concepts about the things narrated by the simplistic scripts. Thus, the scripts function through their interplay with habitual concept formations in academic language games. Nevertheless, it is the live language game that rules, and it produces the scripts that present the results. Human beings' use of reductionist scripting is smart because it enables calculation and precision and control and thus fosters a broad applicability: It furthers controllability and complex constructions.

The machine language on which our IT systems are based is a very special form of symbolic script. Below, we elaborate on the nature of the digital scripts and their implications for the live language games.

\section{Digital language}

\section{Logical positivism}

The logically fuzzy and imprecise language of everyday narration has been under attack by logical positivism with ambitions to replace it with a precise and clear unitary language suitable 
for handling scientific knowledge (Frege 1879 and Whitehead and Russell 1910-13). To do this, logical positivists developed a theory of meaning - the positivist verification theory of meaning - according to which the meaning of a concept, $C$, was the set of observations that would confirm the existence of a thing or phenomenon of type $\mathrm{C}$. The meaning of a word, $C$, would be a set of simple and precise observational statements. In particular, the young Wittgenstein (Tractatus Logico-Philosophicus 1921) analyses the meaning of an expression and how to clarify it by translating it into the symbolic unitary language. Drawing on the symbolic unitary language, complex meanings should be analysed to basic observational statements called elementary (atomic) sentences (1921) in which they then were reassembled logically to constitute the whole meaning. Overall the younger Wittgenstein envisioned a language and a world of logical structures that could be projected (translated) in all kinds of ways, in all kinds of language and phenomena. For instance: the logical structure of a piece of music exists in sound waves, which affect our ears; the same logical structure exists in the vibrations of our eardrums hearing the music, in the score written by the composer and used by the orchestra, it exists in the digital structure of the $\mathrm{CD}$ recordings, in the electromagnetic fluctuations pulsating and controlling in the loudspeaker playing the music, etc. All these phenomena mirror each other because they have the same logical structure. Phenomena are translated by transforming the logical structure into a new medium.

Each elementary sentence does not need to be demonstrated in an axiomatic system but has its own logic. True and false are the basic values that determine the relation between proposition and world. Either the logical structure of the proposition is mirrored in the world, or it is not. Accordingly, the sentences have a two-valued logic and hence the language is digital in nature. The digital nature implies that the truth propositions can be counted and, hence, Wittgenstein's language is quantitative.

\section{Limits of descriptive symbolic language}

Live languages unfold in language games that are based on the development of cognitive habitus. A symbolic language on the other hand is based on a predefined logical grammar that defines which expressions are acceptable and well formed (have meaning) and are clearly either true or false. Logical positivism envisioned symbolic language as expressing everything that is meaningful, that is, everything that we know to be true without leaving room for any speculative clutter and superstition. To filter away the meaningless clutter we need to translate live language sentences into the symbolic language (Ayer 1936). 
However, when we try to do so there are serious problems: The symbolic language is descriptive and only concerned with truth and facts. Live language is concerned with many other things too, such as, possibilities, values and meaning. The sentences in the symbolic language must be true or false, whereas live language is full of concepts with vague borders and many layers of meaning. When complex concepts are represented in a symbolic language, only one of the layers in the conceptual habitus is captured. Nevertheless, the multi-layered understanding is necessary to enable communication between people with different perspectives. Furthermore, such definitions are reductive in that they only concern observational matters. Therefore, to precisely define a concept is to describe an observation function, which tells exactly what to observe in order to observe a real exemplar of the concept. This is the so-called verification theory of the meaning of positivism. Such language only attempts to describe directly observable facts, but even doing that is impossible because of the complexity of an ordinary phenomenon, which makes it impossible to eliminate all complexity and vagueness in observation. The whole empiricist idea of being able to fully reduce complex observation to simple observation is misguided. Perception does not function that way.

Accordingly, the idea of reducing live language meaning to meaning in a symbolic language is not tenable. We need live language when we are using symbolic languages, because we use symbolic languages as elements in our live language, and we cannot do the opposite. If we nevertheless try to replace live language with symbolic language, then we will lose the ability to communicate in practice, because we cannot control the language. Furthermore, we lose our knowledge, because we cannot establish an empirical factual basis, and we lose all the important dimensions of meaning, values and possibilities needed to make sense of our activities. Finally, as reasoning is not a list of facts, the function of reasoning as the basic instrument in coordination and decision making is lost as part of our language and thus of our life form.

Although the project to replace ordinary language with a symbolic digital language through translation was eventually abandoned and replaced by the philosophy of live language (Wittgenstein 1953), it was nevertheless realised in the development of IT during the following century. As we shall see, IT is based on such a form of translation.

\section{IT Language}


IT uses a machine language to control hardware, the machine. The machine language in question is a digital language consisting of binary codes, which are instructions to control the computer. Any program comprises such a system of codes, which define the machine operations according to the intended usage. While the users of a program control the data with which they feed the machine, they cannot change the way the program operates. The users neither know nor understand the digital code that controls the way the machine operates.

In order to produce the machine language of new application programs, IT uses special translation programs (Java, C\#, PHP, etc.). These programs define a symbolic language, a socalled programming language. Each programming language has a specific logical grammar that defines its well-formed sentences. Programmers use this grammar to translate their live ideas into symbolic sentences in that language. When this is done, the program translates the symbolic sentences into a machine code in the form of a new application program.

While the translation from symbolic language to machine language is well defined and difficult to object to, the translation of live ideas into the symbolic language raises serious concerns as illustrated above. These concerns revolve around the meaning of the symbolic sentences differing from that of live sentences, and the fact that they cannot control and replace the live sentences, and also that they are beyond the reach of users who do not know the machine language, but also, largely neither know the symbolic interpretation nor have any authority to influence the interpretation. Accordingly, when the symbolic language takes control it then overrides the cognitive habitus of the practitioners and the professions concerned.

In artificial intelligence (AI) the symbolic approach has been complemented by a sub-symbolic approach that replaces the programmers' production of symbolic sentences in a programming language with processes of machine learning, in which a computer introduced to large quantities of complex phenomena (e.g. images of human beings) is able to learn to identify human beings based on the information it has about the appearance of human beings (Bolander 2019; Bolander 2012). In this way the need for a verification-based definition of the concepts seems to be avoided. However, the resulting 'skills' the computer develops are not based on a conceptual understanding but on the population of exemplars. And that population is normally selected by humans based on their conceptual habitus and biases; thus, the meaning problem is still not solved. We still need live language to reflect and guide the selection of the exemplars. 


\section{The controller}

As long as users are able to combine the use of IT systems with their own live language, the hidden and unchangeable nature of the IT system presents no problem. However, the power of IT also lies in its capability to help users exert control over other users. When IT systems are used to define and control other human beings' practices then the untouchable and hidden nature of the IT language has serious consequences. The more our practices are defined and controlled by untouchable machine codes, the more they control the very meaning of the language of the user, which forces the user language itself to adapt to the reductive translation, that is, to dissolve the habitual cognition, drop reflection, eliminate non-directly observable aspects (value, possibilities, etc.) and drop the usage of live language gaming. If that happens, the advanced cognitive work of the user becomes irrelevant as does the live language game as a source of meaning. This even applies if the user is a researcher and has a far more sophisticated understanding of the topic than has been programmed into the machine. Professional work, including research, becomes ruled by authoritative symbolic scripts rather than through the skill and advanced insight of the professionals.

The interaction between programmers who know how to program, and scholarly practitioners, who know the world as it should be expressed in the symbolic program, produces the translation of knowledge and ideas into a symbolic programming language. When the IT language exerts control then it becomes a reductive monologue communication that detaches the intelligence of employees and others and hence producing poor utilisation of their capacities. If the scholarly practitioners are in some way not a real part of this process, then the whole system works in a similar way as that depicted in Searle's Chinese room ${ }^{4}$, where nobody involved ultimately knows whether anything they claim reflects something real. It is, in the end, only the scholarly practitioners that can distinguish real and fake because they let practice decide. Only practice shows what is real.

\section{Subjective values}

Being considered subjective phenomena, values have been eliminated from the world of facts in the symbolic languages according to logical positivism. This in itself made the symbolic language incapable of use as a language of control. The positivist philosophers developed a

\footnotetext{
${ }^{4} \mathrm{Cf}$. Searle's thought experiment on the 'Chinese room'.
} 
theory called ethical emotivism (Ayer 1936) to cope with the subjective values and thereby reintroduce evaluating elements in the symbolic language to enable it to be used for control purposes. According to emotivism all evaluative expressions like good or bad are considered not as descriptions but as exclamatory expressions akin to expressions such as 'haha' or 'doh'. These expressions can be reported in the symbolic language and thus used in calculating aggregated evaluations by IT systems that are still subjective.

These ideas have apparently led to a widespread evaluation practice asking for likings and subjective reactions on a multiple-choice Likert scale - ranging say from 1 to 5. For instance, users might be asked whether a website is user friendly. But such evaluations are based on pseudo-elementary sentences, which are not descriptive sentences. The method implies that the basis for evaluation is a spontaneous populist expression rather than reason and fairness. The problem with emotivism is that it reduces values and ethics to subjective matters of liking and disliking. In reality, ethics and valuation require reasons why something is considered good or bad.

\section{Conclusion digital language and habitus-based scholarly language}

On this basis we conclude that IT systems are beneficial only when they do not infringe on the epistemological dialectic and harm the social factory. However, when the IT scripting changes from being a tool to support the professionals' cognitive habitus to become a tool used by users to exert control over professionals, it side-lines cognitive habitus and stops epistemological dialectic, and hence there is an infringement on professional work. The digital language takes logos out of the managerial discourse because the concepts and structures are predefined in a reductive script beyond the reach and control of the professionals. By replacing the free habitus-based language game where the meaning is produced in the interaction between people with reductive monologue communication, socialising as well as the cognitive function of language is undermined.

\section{EMPIRICAL ANALYSIS OF UNIVERSITY GOVERNANCE}

This section serves to empirically validate the theoretical argumentation presented above. We analyse the nature of the language in the production and use of IT-based performance measurement as it relates to teaching and research in the corporate university. We then draw 
conclusions about the implications of applying such forms of measurement for the free cognitive conceptual habitus of university scholars. We analyse the language in the scripts producing the teaching and research measures on which the evaluation system is based and the way the measures are used. Finally, we discuss the nature of the governance language game producing the system.

\section{Teaching evaluation}

A metric frequently used at universities for the evaluation of teaching quality is student satisfaction. For instance, in the UK, there are separate national surveys for undergraduate, taught post-graduate, and research students ${ }^{5}$. In addition, students are routinely asked to complete internal surveys about individual taught modules.

\section{Production of student satisfaction measures}

Student satisfaction surveys are dominated by questions on students' experiences of areas such as teaching quality and learning environment. Options are usually presented as multiple-choice answers or on a Likert scale. In the 2017 UK-NSS survey, the questions seem uncontroversial and have clearly been refined over the years (Burgess et al, 2018). For example, one set addresses ${ }^{6}$ assessment and feedback and includes: the criteria used in marking have been clear in advance; marking and assessment has been fair; feedback on my work has been timely; and I have received helpful comments on my work. A 5-point Likert scale from 'definitely agree' to 'definitely disagree' plus a 'not applicable' choice is used, and an average satisfaction score adjusted for the subject mix at the university is calculated.

Using Likert scales to capture students' views on aspects of teaching and the learning environment produces numbers rather than textual answers, which means responses can be presented in the binary digital language of computers. The potential answers are formulated as elementary sentences on the students experience of teaching. Students are asked to choose a number along a 5-point Likert scale. In aggregating these scores, each number implies a degree of 'true or false' for the question. In actuality, this is a series of ones or zeros, multiplied up or

\footnotetext{
${ }^{5}$ https://www.thecompleteuniversityguide.co.uk/universities/choosing-the-right-university/teachingexcellence-framework-(tef)/\#howtheawardsarecalculated

${ }^{6}$ https://www.thestudentsurvey.com/content/NSS2017_Core_Questionnaire.pdf
} 
down to represent 'more likely true' or 'more likely false.' Subsequently, the weighted average score is calculated, making it possible to describe and quantify teaching characteristics, values, and wishes through the digital language of the IT system.

However, the answers are not based on observable fact, but on the students' emotions and subjective values, making the statements produced pseudo-elementary sentences. Thus, user satisfaction surveys are based on their respondents' subjective perceptions of an ideal or a desired service rather than being an objective reference to certain characteristics of the service. The responses thus reflect not only the cognitive abilities of respondents but also their emotional state (Weitz and Wensley, 2002; Teas and Palan, 1997). For instance, as mentioned in the comments on the TEF ranking 'Satisfaction is influenced by prior expectations, so a high satisfaction score could result because expectations of quality were low; equally, a low satisfaction score could arise because expectations were higher than the perceived quality actually delivered. ${ }^{7}$ In addition, student dissatisfaction can express a desire for a more or less challenging or entertaining academic education. It is questionable whether the students are evaluating the academic, pedagogical, or enjoyable qualities of their education. In view of that, it is doubtful whether student satisfaction says anything about the scholarly content of the teaching (Newton 1988; Uttl, White and Gonsales 2017). Teaching quality is a complex phenomenon that is challenging to decompose into measurable units that provide credible information (Clayson and Haley, 2011).

\section{Use of student satisfaction measures}

Student satisfaction measures can be used in different ways. One is a reflective and interactive way, where managers looks for reasons behind the digitally produced numbers. Such a way might interact with the cognitive conceptual habitus of the teacher. However, managers seem increasingly to act on student evaluation reports through the IT system. Thus, management action on the results might also be digitalised.

At the national level, student satisfaction measures might be summed, and the universities ranked. In the UK, the 134 higher education institutions participating in the TEF are awarded a gold, silver or bronze ranking based on their teaching quality ratings (TEF 2018; Neary 2016). The NSS data is supplemented with graduate employment and contextual data. Accordingly,

\footnotetext{
7 thecompleteuniversityguide.co.uk.
} 
the implications of the ratings are rewritten into digital language. A league table reflecting the outcome is publicly available. The national ranking is intended to guide student and parent university choices. Controversially, it does not take into account student entry, and is therefore not a measure of value-added by the university (Neary 2016). The introduction of the TEF was justified on the basis of reports of poor teaching, especially in research-intensive universities but is also used to justify increases in student fees and student loan interest rates imposed by the UK government since 2010 (Neary 2016).

At the university level, student evaluation is included in the periodic performance review of senior faculty and the assessment of whether young faculty should get tenured positions. In some universities, the result is that IT systems reorganise results of student satisfaction surveys on a course into categories of colours such as red, amber and green - a technique used in more commercial or public-sector organisations for appraisal (see for example, Manochin, Brignall, Lowe and Howell 2011). A digitalised message is linked to each colour and is sent by e-mail to the teacher. If the traffic-light system is used, green will be linked to a positive appraisal message, and red linked to a negative appraisal and a request for a digital explanation and future action plan. Amber is often taken as a signal for serious action, with green being regarded as the only acceptable level of performance, meaning that average or satisfactory is not seen as acceptable. Everyone has to be excellent. Hence, we do not have management by reasoning and scholarly interaction but by digitalisation. This digital approach to teaching evaluation is one based on monologue, which implies a systematic crowding out of some relevant and professional knowledge. It excludes the cognitive conceptual habitus of the teachers.

\section{Conclusion}

The preceding research leads us to conclude that student satisfaction measures are based on oversimplified and broad questions on a complex phenomenon such as teaching quality. Nevertheless, in the IT system, the answer options are presented as an elementary sentence that can be true or false, meaning that teaching quality is rewritten into a digital language that does not take into consideration the subjectivity of the statement. The digital language cannot discern the difference between factual-based elementary sentences and pseudo-elementary sentences. Nevertheless, the implication of the measures for actions tend also to be written in digital language. Although, it is questionable whether the measures capture the scholarly content of the course, the IT-based measurement system is treated as authoritative and as a 
monologue. Accordingly, the measurement system supresses the teachers' voices and hence crowds out the cognitive conceptual habitus of university scholars.

\section{Research evaluation}

Research quality is commonly measured in the form of publication points earned. The points are calculated according to the number of journal publications and the quality points assigned to the respective publication, meaning both publication quantity and publication rankings are at the core of calculating publication points. The rankings tend to mainly take account of journal articles while books tend to be excluded. First, we explain how journal rankings and publication points are produced and subsequently how the publication points are used.

\section{Production of journal rankings and publication points}

Lists of journal rankings are commonly produced by professional and organisational associations, government agencies, and commercial entities such as magazines and newspapers. In relation to the production of journal rankings lists within the area of business research in Europe, the following two measurement approaches strongly influence national and university-specific lists: the commercially produced Financial Times journal ranking list and Thomson's Journal Citation ranking. Alongside those are the author-level indexes produced by Google Scholar.

\section{Financial Times ranking}

The Financial Times $(2016)^{8}$ ranking of publications is based on surveys completed by officials from 200 business schools that contribute to one of the Financial Times rankings. All that is known of these business schools is that they should be accredited by AACSB or EQUIS. It is also clear that the outcome of the rankings is that English-language oriented business schools dominate. In 2016, the ranking list was revised; five of the journals on the previous list were removed, and the list was extended from 45 to 50 journals, meaning ten new journals were added. The 200 contributing business schools were invited to nominate five journals to be added and five to be removed. In total, 140 schools responded, and 150 new journals were suggested. Subsequently, the schools were asked to vote for up to five journals they wanted to exclude and for five of the 150 new to be included. The Financial Times decided for unknown

\footnotetext{
8 https://www.ft.com/content/3405a512-5cbb-11e1-8f1f-00144feabdc0
} 
reasons to exclude from the list the four journals that got 60 per cent or more of the votes and add to the list the nine journals with the most votes.

The language of the questionnaire is digital in nature. Embedded in the questionnaire is the binary digital language of computers, where answers to a set of statements are true or false. Thus, the voting for the journals is based on asking the officials of the Business Schools whether a publication belongs to category one or zero, representing whether it should be counted for or not. Subsequently, the number of 'ones' are summed and ranked. However, the statements are pseudo-elementary sentences. They are not basic atomic observational statements, but statements driven by the language games of the school officials.

We do not know the language games of the officials of the business schools producing the ranking lists. But we might question whether a dean with a specific background is capable of evaluating the complexity of cognition within all fields and hence the quality of journals within all fields. Instead of a field-based cognitive conceptual habitus, another type of conceptual habitus might govern. Anyone seeking to obtain some insight into the hidden language games might look at the outcome of the process and note that the selected journals are Englishlanguage journals that are dominated by American scholars, in that $75 \%$ of the editorial board members are from the USA (UK 5\%, Canada 5\%, France 2\%, Australia 2\%, Netherlands 2\%) and $51 \%$ of the papers are published by American authors (UK 12\%, Canada 6\%, France 3\%, Australia 4\%, Netherlands 3\%, Germany 4\%). In addition, the board members of the journals are concentrated around a few American universities and there are considerable interconnections between these universities in that their staff appear on common editorial boards (Burges and Shaw 2010)

Furthermore, the journal ranking lists are biased towards certain research fields and research methodologies (Mingers and Willmott 2012). For instance, organisational behaviour, strategy and enterprise/small business tend to be over-represented, while other business fields are underrepresented or not represented at all (Adler and Harzing 2009; Burges and Shaw 2010). Additionally, some high ranked journals give greater preference to some types of research paradigms or theoretical approaches while excluding others (Merchant 2010, 2012). For instance, Merchant shows that within accounting, 'all types of research other than empirical tests of economics-based models in mainstream areas using large, archival data sets are being starved out of the top-ranked journals' (2010, pp. 117-118). In particular, quantitative empirical 
research accelerated by digitalisation dominates the methodological apparatus of these USbased top-ranked journals. They do not exhibit an intention to relate to technical aspects and core problems of accounting practice and hence not to the conceptual habitus of practice in the accounting profession (Merchant 2010, 2012; Baldvinsdottir, Mitchell and Nørreklit 2010). The research published in highly ranked journals might be neither fundamental nor useful (Kaplan 2018, p.7; Heckman and Moktan 2018).

\section{Journal impact factor}

Highly ranked journals on the Financial Times list are not necessarily widely read (Adler and Harzing 2009), and some commentators argue that journal impact factor offers a better basis for evaluating research. The leading index in the calculation of journal impact factors is Thomson Scientific's JCR (Archambault and Larivière 2009). However, there are other producers of impact factors such as Elsevier (Scopus). The JCR calculates the impact factor of a journal as the number of citations an article receives in the two preceding years divided by the total number of articles published in the journal over the two preceding years ${ }^{9}$. Additional forms include the h-index author-level metric provided by Google Scholar, for instance.

In addition, the impact factor systems are digital in nature. Binary language is embedded in the citations, where a citation/non-citation is perceived as a true/false answer to an elementary sentence statement on whether the article is 'good'. Subsequently, the number of quotes ('ones') are summed and ranked in the system; but those statements are again pseudoelementary sentences. They are statements driven by the cognitive habitus of university scholars and behind the quotes might be a variety of arguments, and moreover, some of the citations of the article might be pointing out its flaws and others highlighting its strengths. This might facilitate a self-full filling prophecy that an article at the top of any list will be cited by others. Accordingly, instead of letting truth be governed by the quality of the argument, truth is governed by the power of mobilising votes.

A crucial contributor to the outcome results are the algorithms calculating the impact factors and the pool of articles that are included in the database (Archambault and Larivière 2009). Thomson's and Elsevier's models for the calculation of impact factors are not neutral but depend upon the framing and data-input of the system. Accordingly, the truth or fallacy of the

\footnotetext{
${ }^{9} \mathrm{http}: / /$ ipscience-help.thomsonreuters.com.
} 
observational points cannot be demonstrated through its own lucidity. Google Scholar has been suggested to offer a better basis for the calculation of impact than some other indexes because it provides a more comprehensive database, however, the coverage of Google is limited.

The language games these producers of impact factors draw upon when creating the models are hidden. But there are data on the extent of bias in the outcome results of the systems. First the source items are biased towards US research approaches, because the system is optimised for the US context. (Archambault and Larivière 2009). Furthermore, a journal impact factor such as the JIF has scores varying tremendously between fields, so for instance, the score for the biomedical field is high while for mathematics or social science it is low (Archambault and Larivière 2009, p. 639). Similarly, highly recognised journals within a small field of research such as management accounting are excluded, because their impact factor is not deemed to be sufficiently high. Additionally, the publisher might assess the suitability of journal editors based on impact factor. In response, journal editors might encourage authors to add references to articles published in their journals (Archambault and Larivière 2009, p. 641; Merchant 2012). In addition, editors might think strategically by boosting numbers of review articles or mainstream papers in their journal.

\section{National and local ranking lists}

Finally, it should be noted that government agencies in for instance the UK, Denmark, and France publish authoritative national ranking lists based on the recommendation of experts. In addition, many universities create their own lists. These local lists can include more journals than the authorative ones, but they are informed by the Financial Times journal ranking and the JCR. In the UK, the current methodology of the Chartered Association of Business Schools (CABS) listing is heavily-based on an amalgam of citation rankings (JCR, SCR and SNIP), moderated by peer-review of the journals by an advisory committee and the editors of the listing. This still leaves unresolved issues of comparability across subject areas, with concerns that a top publication might be easier to achieve in other areas than say in accounting, where five of the top six journals are published in North America.

There is a danger that scholars may feel that lobbying or self-interest have an undue influence on the outcome of the national or local listings. In the Methodology for the Academic Journal Guide published by the Chartered Association of Business Schools in the UK (CABS 2018), it is made clear that the advisory board consult learned societies and other academic institutions 
in making their recommendations. However, it is not always clear to scholars how the lists are compiled.

\section{Publication points}

Increasingly, journal rankings are used by governing bodies to calculate the number of publication points at the level of a university, a department, and for each individual scholar. The calculation might be made in a spreadsheet drawing on journal ranking lists and publication and research databases such as PURE kept by university management to track individual output, which involves capturing and summarising an annual number of incidences for each category to generate a total score. A weighted binary language system is embedded in the scripted language of such spreadsheets. A researcher's publications in certain outlets are observational points that can be a true or false statement, and they are elementary sentences that can be counted. Each publication outlet is given a weight depending on which quality category a journal belongs to. The total publication points are calculated by adding together the weighted set of elementary sentences be that a one or a zero, representing whether it should be counted for or not. The description of the quality of complex scholarly research output is written into elementary sentences that are counted. But the ideal of a basic elementary sentence projecting an objective phenomenon is not evident and instead the response options are pseudoelementary sentences.

\section{Use of journal rankings and publication points}

Actions on research points are in some case purely digitalised. In the Financial Times (2016) rankings of business schools and educational programs (master's degrees, MBAs, and Executive MBAs), the universities research publications points are calculated and weighted into the computation of a total score that is ranked. In Denmark, the universities publication points are calculated and used mechanically for the allocation of research funding to universities. In the case of the allocation of research funding in the UK, the REF (Research Excellence Framework) is applied, which relies on a panel of experts assessing individual papers. The sub-panel for Business and Management states explicitly that the panel will not use journal rankings in its assessments of individual papers (CABS 2018; Pridd and Broadbent 2015; Agyemang and Broadbent 2015). Research clearly reveals that there is no complete correlation between the peer assessment of the reviewers of an individual paper and the ranking of the journal in which the paper was published (Agyemang and Broadbent 2015; Hussain 2015). 
Within universities, managers look at an individual researchers' publication points to assist with performance evaluation. Research points tend to be particularly important to the processes of recruitment and promotion at business schools striving to climb the ranking system. For instance, at the top US schools, having published in highly ranked journals is a requirement for junior faculty members seeking a tenured position and for senior faculty members if they are not to risk becoming marginalised (Merchant 2010). Or as Jérôme Barthélemy, Professor of Management at ESSEC Business School in France puts it: 'In an attempt to exist on the world stage, some schools come to not to care about the research content of the teachers they recruit. Only the number of articles published to increase the number of stars in the rankings counts. It is "publish or perish". The trend is to split research and teaching activities, "a true diversion", (Le Monde 28 Octobre 2018, translated from French).

In the UK, there is controversy around the journal guide produced by the CABS. The initial purpose of the UK list produced by the CABS was benign, in that scholars in business schools from newer universities in particular were unaware of the relative standing of journals in their fields. The aim was to guide such scholars in placing work of say, local or international scope, and perhaps to nurture more ambitious projects. However, the CABS Academic Journal Guide (last updated in 2014 with new journal additions in 2017) has become a fixed point for deans of business schools' decisions on employment and progression (Walker, Fenton, Salter and Salandra 2018; Agyemang and Broadbent 2015; Hussain 2011). They rely on the list as a way of comparing colleagues over the different subject areas found within business schools, rather than relying on those within the group to assess the work. In addition, there are known examples in the UK where workload hours for research are allocated on a points basis (for example, a paper in a journal ranked ' 3 ' on the CABS Academic Journal Guide accrues three points). Furthermore, there are cases where promotion criteria are based on a threshold comprising a combination of journal rankings of papers, teaching scores from student satisfaction surveys and total grant income awarded. But as the managers of the corporate university are given authority, the actual language game through which the publication points are decided upon in relation to recruitment and promotion is often hidden.

Moreover, the journal guide is conflated with decisions about which papers to submit to the REF despite the fact that journal rankings are not used in the assessments of individual papers. For Agyeman and Broadbent (2015), this constitutes a form of symbolic violence, that can 
unduly influence management decisions. Overall, the adjective 'REF-able' dominates university discourse. The term means that one has enough publications of sufficient quality within the REF period (five to six years) to be included in the department's submission to the REF. However, this might not be sufficient, because the publications have to be three or four stars in order to be 'internationally excellent' (McCulloch 2017; Hussain 2015) The REF2021 draft criteria are designed to ameliorate some of the game-playing that has clearly happened in the past (such as excluding some staff when they do not have four publications, 'buying in' staff on fractional contracts near the submission date). However, it requires all papers to be pooled, with each 'independent researcher' submitting a minimum of one and a maximum of five papers, with an average of 2.5 across a unit of assessment. Subtly, though, this decoupling gives ownership of the research to the university rather than to the author, the implication being that the 'excellence' of the university research environment enabled the work to be produced rather than the researcher enabling the university to create the excellent research environment. This 'counting', which translates itself into spreadsheets and databases such as PURE kept by management to track quantity and rankings of outputs, reinforces the notion that the individual academic can be described in digital language. 'The picture that emerges is one in which academics are positioned as managed professionals whose personal goals are expected to be closely aligned with the university's objectives to perform well in the REF, move up the league tables, attract students and secure income' (McCulloch 2017). Along with this, an overwhelming observation is that the communication style of business school academics is changing; now, instead of speaking of the topic or content of their past papers, the most common statement is along the lines of, 'I have one 4* and three 3's'. Another variation on the communication is, 'are you REF-able?' and the response is likely to reference journal list rankings (Walker et al 2018; McCulloch 2017).

One consequence of the digital approach to research evaluation is a systematic crowding out of some relevant and professional knowledge. As mentioned above, some fields and topics dominate the top-journal ranking lists, while others are more or less non-existent. Hence, some fields might attract a disproportionate number of scholars. As Archambault and Larivière (2009, p. 639) stated: 'To careful users of the JIF, it becomes clear that schemes such as these are helping researchers in the biomedical field become wealthier (because these fields have high citation rates and therefore high non-normalised impact factor values), while others, such as mathematicians or social scientists, are obtaining only small bonuses'. Or as reported by McCulloch (2017): 'a professor in marketing decided to target management journals instead of 
marketing journals because that is an easier "way of hitting a four star" (see also Hussain 2015). As the top-ranked journals are biased in favour of certain fields and appear to have little interest in reporting relevant research for practice, they might contribute to the crowding out of staff holding relevant knowledge for teaching. The implication is that regardless of the journal, ranking tables might have a bias towards certain fields and research that is less relevant to teaching for practice, and they govern the assessment and recruitment process (Walker et al 2018; Agyeman and Broadbent 2015). Prior research also confirms that important decisions tend to be outsourced to bodies external to the particular university context, who do not know or care about the university and its stakeholders (Kaplan 2018).

As a final point, significant issues arise with regard to how the lists are used by management in business schools to marginalise some scholars. There have, for instance, been allegations that the lists have been used in bullying and harassment cases, and there are specific reports of the intimidation of faculty who are committed to teaching or who are not REF-able. Instances cited include hierarchical dualism (Boje, Rosile, Dennehy and Summers 1997), and placing the 'REF-able' scholars above the teaching scholars in the organisational hierarchicy, which indicates that publishing in top-ranked journals is more important than passing relevant knowledge on to students. Scholars publishing in top-ranked journals are 'living like a mercenary star who goes from one international conference to another (...) and avoiding teaching...' (Barthélemy 2018). Meanwhile, those who do not publish in such journals might be re-graded to teaching only professors. But as journal rankings drives recruitment that matches research output rather than teaching needs, there tend to be tensions in university departments about the recruitment of people who can teach and people who cannot. Nevertheless, when scholars raise concerns to responsible managers they perceive themselves to be met with harassment and intimidation. The Guardian newspaper has reported a widespread culture of bullying at UK universities: 'Research staff who had fallen out of favour would routinely be denigrated behind their backs, and her boss responded with explosive anger to scientific setbacks and made comments seemingly designed to humiliate. "She'd ask the impossible and get really angry when you said no. Too much was never enough," she said. 'People would be in tears.' (...) The head of department was aware of the problem but had an attitude of "just take it on the chin and get on with it",' (Guardian 2018). Thus, when handling actual problems experienced by the academic staff, there is evidence that managers might counter sound arguments offered with more insubstantial argumentation. 


\section{Conclusion}

It is evident that the evaluation of university research quality is dominated by standards and criteria formulated through a network of digital language systems. The language system is digital in nature in that it is based on a set of statements for which there is a binary choice of a true or false answer. At the surface level, the statements might look like elementary sentences; however, the elementary sentences are pseudo in nature, because they are not basic atomic observational statements. They are based on another IT-based scripted language designed by external agents. The unitary digital language implies that the qualities of the various professional fields can be made into standard comparable units measured by the same measurement norm. Accordingly, recruitment and promotion-based on research publications points make it possible for managers without specialist knowledge to form an opinion of an applicant, without having to elicit the opinion of scholars in the field.

A consequence of the digitalised use of IT-based performance measurement systems is the lack of logos of any depth. The digital management approach contributes to a research-teachingpractice gap, but the management can detach themselves from this through the IT system and insubstantial argumentation. The utilisation of professional comments of academics on the quality of knowledge in their field is discarded in favour of more reductive metrics that can be incorporated more easily into an IT system for the purposes of ranking rather than matching the needs of teaching. The production and use of what is deemed good and that deemed bad research is driven by a hidden reasoning that involves self-interest and is executed by hierarchical power. In such an environment with poor logos, intimidation and harassment can flourish.

Accordingly, the use of IT systems has created an impetus to implement digital scripted systems as instruments for hierarchical control of the conceptual habitus of university scholars. Professional habitus is supplanted with a control habitus concerned with outmanoeuvring the habitus of scholars.

\section{Discussion findings}

Overall, the analysis demonstrates that management by IT system interferes with and inhibits the function of the social factory by taking control of the concepts and language of social interaction. The result of an undermining of the social interaction with the conceptual habitus might be a life in a world resembling that of the Chinese room, described by the philosopher 
John Searle (1980), who outlined a world of delusion in his thought experiment of the same name. Applying this analogy, university scholars are controlled by a network of chambers of delusion - a world controlled by symbolic numbers. The managers in the chambers are locked in. They only speak the scripted language of the IT system, which is based on a set of pseudoelementary sentences for which there is a binary choice of answer of zero or one. The categories of the IT system shape the inboxes. The system has a dictionary expressing rules for translating the language of research practices into the symbolic language of numbers. The rules of the dictionary are made by a hidden language game produced by a largely invisible management power. The managers cannot touch or see the researchers' practical situation. The managers communicate with the researchers by receiving messages in their inboxes and translating them according to a flexible rulebook and then delivering the translation to an outbox from where researchers are expected to collect it and action it. Outside the rooms are researchers using different languages who must act based on the communication through the managers translations. They do not know the rules shaping the dictionary that translates messages from one language to another. But although the managers do not, the researchers might know what the practice is about.

We see in the construction of the chamber of delusions the contour of social relationships governed by an auction model (Levin 2004). With regard to research, university scholars are bidders and a network of managers makes the auction rules through the scripted language of an IT system. There is one object to be sold: publications on the journal authority list. There are many bidders, that is, university scholars aiming to publish. Those bidders have incomplete information about the auction rules; the rules of the game are hidden and variable. Nevertheless, the auction system gives rise to a competitive game between the universities and the scholars that is in the economic interest of a largely invisible management power. The group of scholars that subscribe most wholeheartedly to the invisible management power is 'excellent,' but not only the scholars who achieved their objective pay, but also those who do not. It is about being a winner or loser in the university job market and about social dominance. Accordingly, the auction system determines who for the time being are the excellent participants and who will be marginalised.

A special feature of such a comprehensive digital form of control is that it involves control over the language and the meaning of words. The professionals - and indeed anybody else lose their control over the meaning of their language. This enables managerial control to 
produce fictional results by changing the rules of language by changing the criteria and definitions. The management culture keeps rebels focusing on relevance in their place by deploying insubstantial argumentation and systematic emotional attacks to ensure that the dissenters become the wrongdoers. Such a systematic delusional management approach detaches university activities from vital professional practices, which combined with hostile actions against professional academics raising legitimate concerns, constitute a bullying management approach.

It is important to note that language only functions if people can trust what the words mean. As soon as there is some remote control of the meaning of words and that remote control is always directed to manipulate the meaning of words, then employees' conceptual habitus will be sidelined. What appears to be logos is most likely no longer trustworthy as logos. When logos is excluded from managerial communication, only ethos and pathos are left, which opens the space for a post-truth culture with scant regard for truth (D'Ancona).

\section{CONCLUSION}

The current article has examined whether the IT-based performance measurement models applied in the governance of the corporate university crowd out habitus-based scholarly language. We began by theoretically explaining how a pragmatic functioning social factory is developed through co-authorship, which involves the narratives and narrations of the actors' live language game through which they produce and develop complex cognitive conceptual habitus. However, such conceptual habitus may be destroyed when the reductive, symbolic conceptualisation in the digital language of the IT system becomes a tool that controls professionals. The digital language takes logos out of the managerial discourse and hence sidelines the cognitive habitus and halts the epistemological dialectic. Subsequently, the study examined developments in the IT-based performance measurement systems that influence actual university governance. We found that university scholars are governed by standards and criteria formulated by a network of digital language systems. The digital language with its pseudo-elementary sentences and hidden agenda of control interferes with and inhibits the social factory of universities by taking control of the concepts and language of the social. Where a digital language takes control, we see a weakening scholarly cognitive habitus, which leads to a decline in the role of logos in argumentation. We conclude that the digital language 
of the IT system is taking over the free cognitive conceptual habitus and scholarly argumentation

Accordingly, the post-truth elements not only influence the media and political culture, but also the culture of the corporate university. The situation constitutes a threat to the unique role of universities (in that they are the institutions that provide the foundation for a scientific basis for our secular society) and hence the whole project of enlightenment and knowledge-based society is in danger of losing its institutional foundation; even worse, then the institutional foundations may promote deception and forge beliefs of a totally irrational character. Science has demonstrated that humans are not purely rational beings and tries to provide instruments with which to understand the irrational elements. But if science itself is an irrational element in the sense above, then society is based on superstition and make believe, and the basis for reasonable critique and improvement of social power will be undermined. In such a post-truth situation there can be no ethics. The findings of the current research accord with those of Wittgenstein (1921) in Tractatus Logico-Philosophicus that the subject, meaning, ethics, etc. must be outside the world. We appear to have reached such a post-truth condition state, where rational thought and ethics are without value.

We reveal that adopting the digital language of performance measures has wider implications than to discipline the scholars of the corporate university and accelerate their output results (Alvesson and Spicer 2016; Humphrey and Gendron 2015). Increasingly, the digital-based performance measurement of university scholars teaching and research is undermining their self-controlling abilities and inhibiting the social factory of universities. Hence, they are disarmed and unable to engage in any critical dispute (Worthington and Hodgson 2005; Anderson 2008). It is questionable whether 'between us, as a collegiate, we have the bases covered' Barcan (2013). The production and use of IT-based measurement systems seem to be driven by hidden interests detached from local practice, while university managers do not appear to be concerned about the pragmatic implications of their approach for practice. Ironically, politicians and practitioners call for applicable research and teaching relevant for practice, but they cannot see what is going on, as the numbers employed by IT systems also dilutes the institutional environment (Craig et al. 2014). Accordingly our findings are consistent with the psychotic features within the audit culture of universities (Craig et al. 2014). 
Although our findings focus on the IT-based performance measurement system in some European universities, we see the widespread use of the scripted language of spreadsheets for the control of professionals across disciplines and institutions. Our study puts forward a conceptual model for understanding the recent development towards a digital discourse. The theoretical model is created in a conceptual form that makes it possible for anyone interested to trial it in another context. Furthermore, a description of the context of the university performance measurement system provides the reader with knowledge of the sites to which the conceptual framework is applied, thus providing a pre-understanding of whether it is reasonable for the reader to assume that 'generalization can, and cannot, be extended' to another setting (Payne and Williams 2005, p.310).

Nevertheless, other forms of management narratives may be possible. However, we have major concerns. First, digitalisation is penetrating almost all types of human activity worldwide (Snabe 2015), and the power of IT should not be underestimated (Musk 2017). In relation to management, an IT system provides technological power that can exercise control to an extent, in that it can detail what the employees must do, while managers might invoke motivational action among employees by exerting emotional pressure, for instance by formulating unrealistic and ambiguous targets, and linking punishment and rewards to the degree of achievement. Hence management can exert hierarchical disciplining power on peoples' actions as if they were programmed robots; whether or not it is appropriate. Furthermore, people are anxious to become a lose at the job market and try to avoid being labelled as wrongdoer and. Thus, the power of managers is re-enforced by the fear the digital-based governance process produces. The uneasiness of living in the expectation of attack adds to the fear within the posttruth culture, and thus motivates people to adapt rather than to be victimised. Perhaps it will take years before a destructive attack takes place on the more or less hidden power of digital based governance which may retain the strength to resist for a considerable time.

Nevertheless, we need further research on the effect of such primitive yet powerful instrumental language games and how to oppose such developments. In particular, it could be fruitful to investigate the possibility of withdrawing from the post-truth culture. Thus a new form of language game might enable us to escape the culture of post-truth.

\section{Literature}


AACSB International - The Association to Advance Collegiate Schools of Business (2018) Eligibility Procedures and Accreditation Standards for Business Accreditation https://www.aacsb.edu/-/media/aacsb/docs/accreditation/standards/2018-businessstandards.ashx?la $=$ en

Adler N.J. and Harzing A-W (2009) When knowledge wins: Transcending the sense and nonsense of academic rankings, Academy of Management Learning and Education, 8 (1)

Alvesson, M., and Spicer, A. (2016). (Un) Conditional surrender? Why do professionals willingly comply with managerialism. Journal of Organizational Change Management, 29(1), 29-45.

Agyemang, G., and Broadbent, J. (2015). Management control systems and research management in universities: An empirical and conceptual exploration. Accounting, Auditing and Accountability Journal, 28(7), 1018-1046.

Anderson, G. (2008). Mapping academic resistance in the managerial university. Organization, 15(2), 251-270.

Archambault and Larivière: (2009) History of the journal impact factor: Contingencies and consequences Scientometrics 79

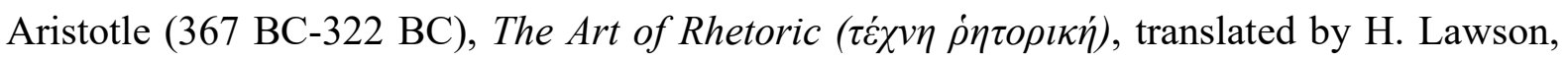
Penguin, London (1991).

Ayer, A.J. Language Truth and Logic, 1936 London Gollancz

Barthélemy, Jérôme (2018) Le Monde, 28 Octobre

Bachan, R. (2017) Grade inflation in UK higher education. Studies in Higher Education, 42(8), pp. 1580-1600.

Baldvinsdottir, G., Mitchell, F., and Nørreklit, H. (2010). Issues in the relationship between theory and practice in management accounting. Management Accounting Research, 21(2), 79-82.

Barcan, R. (2013) Academic life and labour in the new university: Hope and other choices. Abingdon: Routledge.

Boje,D.M.,Rosile,G.A.,Dennehy,R.,andSummers,D.J.(1997).Restorying reengineering some deconstructions and postmodern alternatives. Communication Research, 24(6).

Benson R., Constable G., Lanham C. D (1991) Renaissance and Reneval in the 12century, University of Toronto, Canada

Bloch, C. (2016). Passion and paranoia: Emotions and the culture of emotion in academia. Routledge. 
Bolander, T. (2020) What do we lose when machines make decisions, Journal of Mangement and Governance, 24.

Bolander, T. (2019) Human vs machine intelligence, Proceedings of Pragmatic Constructivism, 9(1), 17-24.

Bourdieu, P. (1990). The Logic of Practice. Polity Press.

Burges T. F. and Shaw N. E. (2010) Editorial Board Membership of Management and Business Journals, British Journal of Management, 21, 3, pp.627-648.

Burgess A, Senior C and Moores E. (2018) A 10-year case study on the changing determinants of university student satisfaction in the UK. PLoS ONE 13(2): e0192976. https://doi.org/10.1371/journal.pone.0192976

Burrows, R. (2012) Living with the h-index? Metric assemblages in the contemporary academy. The Sociological Review, 60(2), pp. 355-372.

CABS (2018) Academic Journal Guide 2018: Methodology, London: CABS. Available online at https://charteredabs.org/academic-journal-guide-2018/

Clayson, D.E. and Haley, D.A. (2011) Are Students Telling Us the Truth? A Critical Look at the Student Evaluation of Teaching. Marketing Education Review, vol. 21, no. 2, 101112

Craig, R., Amernic, J., and Tourish, D. (2014) Perverse audit culture and accountability of the modern public university. Financial Accountability and Management, 30(1), pp. 1-24.

D'Ancona, M. (2016) Post-Truth: The new war on truth and how to fight back. London: Ebury Press.

Financial Times (2016)nhttps://www.ft.com/content/3405a512-5cbb-11e1-8f1f-00144feabdc0

Franco-Santos M. and Doherty N. (2017) Performance management and well-being: a close look at the changing nature of the UK higher education workplace, The International Journal of Human Resource Management, 28:16, 2319-2350,

Frege, G. (1879) Begriffsschrift, eine der arithmetischen nachgebildete Formelsprache des reinen Denkens. Nebert, Halle (Reprinted in Angelelli (ed.) (1988, I-88))

Gill, R. (2009) Breaking the silence: The hidden injuries of neo-liberal academia. In: Flood R and Gill R (eds.) Secrecy and silence in the research process: Feminist reflections. London: Routledge, pp. 228-244.

Gendron, Y. (2015) Accounting academia and the threat of the paying-off mentality. Critical Perspectives on Accounting, 26, 168-176. 
Heckman J. and Moktan S. (2018) Reliance on the T5 to screen talent incentivizes careerism over creativity. IZA Institute of Labor Economics, October, http://ftp.iza.org/dp11868.pdf

Humphrey, C., and Gendron, Y. (2015) What is going on? The sustainability of accounting academia. Critical Perspectives on Accounting, (26), 47-66.

Hussain, S. (2011) Food for thought on the ABS academic journal quality guide. Accounting Education, 20 (6), pp.545-559.

Hussain, S. (2015) Journal list fetishism and the 'sign of 4'in the ABS guide: A question of trust?. Organization, 22 (1), pp.119-138.

Kalfa, S., Wilkinson, A., and Gollan, P. J. (2018) The academic game: Compliance and resistance in universities. Work, Employment and Society, 32(2), 274-291.

Kaplan R. (2018) Reverse the Curse of the Top-5, Harvard Business School, Working Paper $19-052$

Kristensen J.E., Nørreklit, H., and Raffnsøe-Møller, M. (2011) University performance management at Danish universities. Copenhagen: DJOEF.

Levin J. (2004), Auction Theory, https://web.stanford.edu/ jdlevin/Econ\%20286/Auctions.pdf

Manochin, M., Brignall, S., Lowe, A., and Howell, C. (2011). Visual modes of governmentality: Traffic lights in a housing association. Management Accounting Research, 22 (1), pp.26-35

McCulloch S. (2017) The importance of being REF-able: academic writing under pressure from a culture of counting Available online at: http://blogs.lse.ac.uk/impactofsocialsciences/2017/02/09/the-importance-of-being-refable-academic-writing-under-pressure-from-a-culture-of-counting/.

Mejlgaard, N., K. Aagaard and K. Siune (2002). Politik og Forskning forskningspolitik mellem autonomi og heteremoni. Analyseinstitut for forskning. No. 8.

Merchant, KA. (2010) Paradigms in Accounting Research: A View from North America Management Accounting Research, 21(2), pp. 116-120.

Messner, M. (2009) The limits of accountability. Accounting, Organizations and Society, 34(8), pp. 918-938.

Mingers, J. and Willmott, H. (2012) Taylorizing business school research: On the 'one best way’ performative effects of journal ranking lists, Employee Relations 6: 8, pp. 10511073. 
Musk, E. (2017) https://twitter.com/elonmusk/status/896166762361704450?lang=da (Aug. 2017)

Neary, M. (2016) Teaching Excellence Framework: a critical response and an alternative future. Journal of Contemporary European Research, 12 (3).

Newton, J.D. (1988) Using student evaluation of teaching in administrative control: The validity problem. Journal of Accounting Education, vol. 6, no. 1, 1-14

Nørreklit, H., Nørreklit, L., and Mitchell, F. (2010) Towards a paradigmatic foundation for accounting practice. Accounting, Auditing and Accountability Journal, 23(6), 733-758.

Nørreklit, L. (2011) Actors and reality: a conceptual framework for creative governance. In: Jakobsen M, Johanson I-L and Nørreklit H (eds) An Actor's Approach to Management: Conceptual Framework and Company Practices. Copenhagen: DJOEF, pp. 7-37.

Nørreklit, L. (2017a) Paradigm of Pragmatic constructivism. In: Nørreklit H (ed) A philosophy of management accounting: A pragmatic constructivist approach. London: Routledge, pp. 21-94.

Nørreklit, L. (2017b) "Paranoia and Control. A Narrative about the Social Factory." In: Hepp, R.D., Kergel, D., and Riesinger, R. (eds) Social Vulnarability. Hyperprecarization and Social Structural Transformations in European Societies. Springer. Wiesbaden. (Forthcoming).

O’Neil, K. (2016) Weapons of Math Destruction, New York, Crown Random House

Payne, G. and Williams M., (2005), Generalisation in qualitative research, Sociology . Vol. 39, No 2., pp. 295-314.

Pianezzi D., Nørreklit H. and Cinquni L. (Forthcoming) Academia after virtue: An Inquiry into the Moral Character(s) of Academia. Journal of Business Ethics,

Pidd, M., and Broadbent, J. (2015). Business and management studies in the 2014 Research Excellence Framework. British Journal of Management, 26(4), 569-581.

Readings, B. (1996) The university in ruins. Boston, MA: Harvard University Press.

Searle, J. (1980) Minds, Brains and Programs. Behavioral and Brain Sciences, 3 (3): 417-457.

Snabe, J. (2015) https://www.weforum.org/agenda/2015/11/what-will-digitalization-do-tothe-future/ (August 2017)

Teas, R.K., and Palan, K.M. (1997) "The realms of scientific meaning framework for constructing theoretically meaningful nominal definitions of marketing concepts", The Journal of Marketing, 61(2), pp. 52-67

TEF (2018) https://www.thecompleteuniversityguide.co.uk/universities/choosing-the-rightuniversity/teaching-excellence-framework-(tef)/\#howtheawardsarecalculated 
The Guardian (2018) https://www.theguardian.com/education/2018/sep/28/academics-ukuniversities-accused-bullying-students-colleagues

Thomson

http://ipscience-

help.thomsonreuters.com/inCites2Live/indicatorsGroup/aboutHandbook/usingCitationI ndicatorsWisely/jif.html

Thrift, N. (2005) Knowing capitalism. London: Sage.

Uttl, B., White, C.A.and Gonsales, D.W. (2017) Meta-analysis of faculty's teaching effectiveness: Student evaluation of teaching ratings and student learning are not related. , September 2017,

Walker, J. T., Fenton, E., Salter, A., and Salandra, R. (2018) What Influences Business Academics' Use of the Association of Business Schools (ABS) List? Evidence from a Survey of UK Academics. British Journal of Management.

Weitz, B.A. and Wensley, R. (2002) Handbook in Marketing, Sage Publication, London.

Whitehead AR and Russell BB (1910-13) Principia Mathematica.

Wittgenstein, L. (1921) Tractatus Logico-Philosophicus. In Annalen der Naturphilosophie. English translation by D. F. Pears and B. F. McGuinnes, Routledge and Kegan Paul, London and Henley, (1961).

Wittgenstein, L. (1953) Philosophical Investigations translated by G.E.M. Anscombe, Basil Blackwell, Oxford.

Worthington, F., and Hodgson, J. (2005) Academic labour and the politics of quality in higher education: a critical evaluation of the conditions of possibility of resistance. Critical Quarterly, 47(1-2), 96-110. 